\title{
Relation between clinical features and gastric emptying time in diabetic patients
}

Hamid Javadi', Hoda Bayani', Mehdi Mogharrabi ${ }^{1}$, Ali Mahmoud Pashazadeh², Shahriar Semnani', Zeinab Alipour ${ }^{3}$, Iraj Nabipour ${ }^{3}$, Majid Assadi²

${ }^{1}$ Golestan Research Center of Gastroenterology and Hepatology (GRCGH), Golestan University of Medical Sciences (GUOMS), Gorgan, Iran ${ }^{2}$ The Persian Gulf Nuclear Medicine Research Center, Bushehr University of Medical Sciences, Bushehr, Iran

${ }^{3}$ The Persian Gulf Tropical and Infectious Diseases Research Centre, Bushehr University of Medical Sciences, Bushehr, Iran

The authors declare that they have no conflict of interest.

[Received 19 II 2014; Accepted 19 XII 2014]

\begin{abstract}
BACKGROUND: Gastroparesis is characterized by delayed gastric emptying. This pathology is usually observed in patients with diabetes. One standard approach to quantitative assessment of gastric emptying is scintigraphic study. The aim of present study was to perform scintigraphic study of gastric emptying time in patient with diabetes and to find its correlation with patients' characteristics.

MATERIALS AND METHODS: Gastric emptying was assessed in 19 patients with type 2 diabetes (mean age of $61.04 \pm 6.09$ years) and 6 healthy volunteers. Characteristics of the patients were sex, age, duration of diabetes, blood sugar and serum $\mathrm{HbA}_{1 \mathrm{c}}$ level.

RESULTS: Results of present study revealed that gastric emptying half time was significantly larger in patients with type 2 diabetes as compared with healthy volunteers ( $P$-value $<0.05)$. While correlation of sex, age, duration of diabetes and blood sugar with gastric emptying time was not statistically significant, $\mathrm{HbA}_{1 \mathrm{c}}$ level had significant effect on gastric emptying time. CONCLUSION: Results of this prospective study indicated that level of serum $\mathrm{HbA}_{1 \mathrm{c}}$ is an effecting factor on gastric emptying time in patients with type 2 diabetes; however, these preliminary findings should be validated in larger and well-designed studies.
\end{abstract}

KEY words: gastroparesis, gastric emptying, diabetes, radionuclide imaging

Nuclear Med Rev 2015; 18, 1: 3-6

\section{Background}

Gastroparesis is a gastric related chronic disorder which is associated with delayed emptying of solids/liquids from the stomach. It is estimated that about $4 \%$ of the population suffer from gastroparesis [1].

One of the observed cases of gastroparesis is among the patients with diabetes. Results of the studies report gastroparesis in patients with diabetes, but predictors of gastric emptying in these patients are not well defined [2-6] and relationship between rate of gastric emptying and their clinical and biochemical symptoms is usually weak $[4,5,7]$. Therefore it is usually suggested to do objective measurement in order to establish more exact diagnosis of gastroparesis [3].

Correspondence to: Majid Assadi, MD

The Persian Gulf Nuclear Medicine Research Center

The Persian Gulf Biomedical sciences Institute

Boostan 19 Alley , Sangi Street, Bushehr, Iran

Phone: 0098-771-2580169

Fax: 0098-771-2541828

E-mail: assadipoya@yahoo.com, asadi@bpums.ac.ir
Scintigraphy of gastric emptying is a common procedure to evaluate patients with symptoms of alteration of gastric emptying [8]. Since the first application of radionuclide imaging to evaluate gastric emptying in 1966, it has become the standard method in clinical practice owning to its capability to provide a noninvasive method to quantitative study of gastric emptying [9]. In this method radio labeled solid or liquid meal is used to provide gastric count of the stomach as an indicator of gastric dysfunction.

Based on the results of radionuclide imaging of gastric emptying in patients with diabetes, delayed gastric emptying has been reported in $25-55 \%$ of patients with type 1 diabetes, and $30 \%$ of patients with type 2 diabetes $[10,11]$. In other study performed on patients with gastroparesis, diabetes was reported in $29 \%$ of cases [12].

It is indicated that various characteristics of the patients with diabetes may influence gastric emptying time. It is established that, for example, acute changes in concentration of blood glucose may affect gastric emptying of both solid meal and liquid meal in patients with diabetes [13].

In this effort we were going to perform scintigraphic study of delayed gastric emptying in patients with diabetes and to assess the 
effect of sex, age, blood sugar, duration of diabetes and serum level of $\mathrm{HbA}_{1 \mathrm{c}}$ (Hemoglobin $\mathrm{A}_{1 \mathrm{c}}$ ) as important detrimental factors on gastric emptying time.

\section{Materials and methods}

Nineteen type 2 diabetic patients (9 men and 10 women) with a mean age of 61.04 years $( \pm S D=6.09$ ) who were referred to the gastroenterology clinic at our hospital were invited to participate in our study. Also, 6 healthy volunteers without gastrointestinal symptoms were considered as control group of present study.

Exclusion criteria in this study was metabolic disorders (hypothyroidism, kidney failure and liver failure), rheumatic diseases (scleroderma and lupus), heart disease ( $\mathrm{Ml}$, heart failure and heart valve problems), history of surgery effecting on gastric emptying (vagotomy, gastric bypass), history of PUD (Peptic Ulcer Disease) and use of drugs affecting gastric emptying (anticholinergics, prokinetic drugs and opioids).

This study complies with the Declaration of Helsinki, and it was approved by the institutional ethics committee of our research institute. Before the study, in order to be aware of the study, whole of the procedure was explained to all of the patients and healthy individuals and consent form was signed by them satisfactorily. They also had option to withdraw from the study at any time they desired.

In order to reduce effect of diurnal activates on gastric emptying, the study was conducted in the morning. On the day of the study, blood glucose concentration of each patient was checked to be in the range of 3.5 to $9.0 \mathrm{mmol} / \mathrm{L}$. Each patient was given a test meal

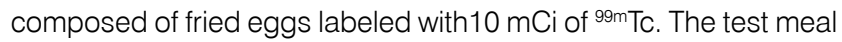
was served to the patient with $150 \mathrm{~mL}$ non-labeled water.

In order to study gastric emptying by scintigraphy, scanning was started for each patient immediately after ingestion (time 0) continued for a couple of minutes. The study was reaped every 30 minutes over 120 minutes (total number of 5 measurements for each case). The scintigraphic data was acquired in anterior and posterior projections in a fixed supine position. Region of interest of the stomach was drawn visually for the first frame and then replicated on later images. Data acquisitions were performed by a Gamma camera (Pegsys, ADAC laboratory, USA) equipped with a low-energy high-resolution collimator.

Geometric mean of the recorded activities of the frames were plotted against time to determine gastric emptying time and gastric emptying halftime $\left(T_{1 / 2}\right)$ as the time point at which the amount of the activity of the stomach reaches to $50 \%$ of its maximum activity. Gastric empting half time is a common parameter for scintigraphic studying of gastric emptying. Based on the types of the radio labeled meal, this parameter may range from 36 minutes to 169 minutes [14].

All measurements were corrected for radionuclide decay by multiplying recorded activities to its corresponding decay factor (DF). Decay factor expressed as:

$$
\mathrm{DF}=\exp (-\ln 2 \times \mathrm{t} / 361)
$$

where $t$ is the time (minutes) elapsed after the first measurement.

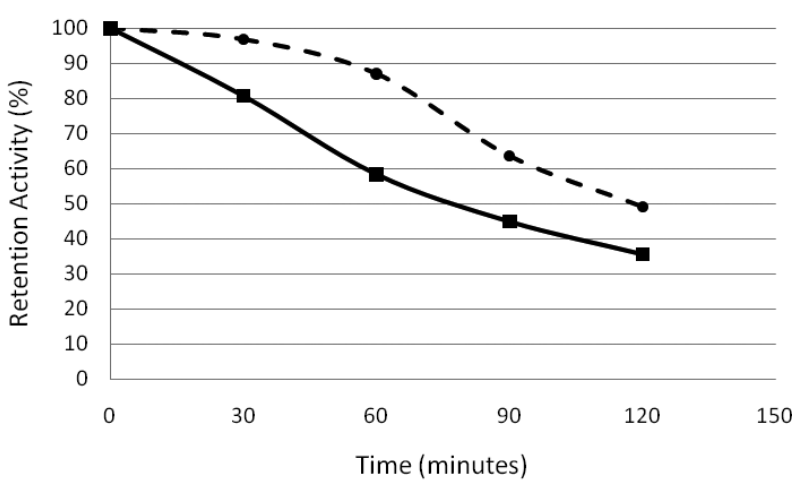

Figure 1. Gastric emptying curve in patients with diabetes (dashed line) and in healthy subject (solid line)

\section{Statistical analysis}

All data were expressed as the mean $\pm \mathrm{SD}$, with ranges given when appropriate. Continuous variables were compared by using the unpaired t-test, and categorical variables were compared by using the chi-square analysis. Spearman correlation of independent variables was calculated with gastric emptying time as dependent one.

A P value of less than 0.05 was considered to be statistically significant. The SPSS for Windows software package (Release 18, SPSS Inc., Chicago, Illinois) was used for the statistical analysis.

\section{Results}

In order to compare gastric emptying time in patients with diabetes with normal volunteers, gastric emptying half time of these two groups was calculated. Based on this analysis, gastric emptying in patients with diabetes (118.38 \pm 23.58 hours) was significantly slower than in healthy subjects $(88.00 \pm 10.00$ hours $)$ (P-value $<0.05)$. Figure 1 demonstrates gastric emptying curves of these two groups.

In patients with diabetes suffering from delayed gastric emptying, observed clinical symptoms was as follows: asymptomatic $(30.4 \%)$, flatulence $(26.1 \%)$, early satiety (13\%) and the rest was a mixture of two or more of above mentioned symptoms.

Mean of the baseline characteristics of patients with diabetes and their correlation with gastric emptying time are presented in Table 1.

In order to assess effect of sex on gastric emptying in diabetic patients, male and female patients were categorized and analyzed in two separate groups. Results of this analysis indicated that with respect to gastric emptying time, there is no significant difference between these two groups ( $P$-value $=0.368$ ). We also found that mean gastric emptying time in diabetic patients is not correlated to the age of the patients ( $P$-value $=0.400$ ).

Laboratory findings of the patients with diabetes were also evaluated. Statistical analysis of these data revealed that there was no significant correlation between blood sugar concentration and gastric emptying time of the patients with diabetes ( $P$-value $=0.869$ ). But we observed that $\mathrm{HbA}_{1 \mathrm{c}}$ level was statistically correlated to the gastric emptying time (P-value $<0.05)$. 
Table 1. Baseline characteristics of patients and their correlation with gastric emptying time

\begin{tabular}{|c|c|c|c|c|c|}
\hline & Sex & Age (years) & $\begin{array}{l}\text { Blood glucose } \\
{[\mathrm{mmol} / \mathrm{l}]}\end{array}$ & Hb1AC level & $\begin{array}{l}\text { Duration of diabetes } \\
\text { (years) }\end{array}$ \\
\hline Mean $\pm \mathrm{SD}$ & - & $60.04 \pm 6.09$ & $165.5 \pm 19.17$ & $9.6 \pm 2.07$ & $9.76 \pm 6.81$ \\
\hline Correlation with $\mathrm{GET}^{\star}$ (P-value) & Negative (0.368) & Negative $(0.400)$ & Negative (0.869) & Positive (0.02) & Negative (0.148) \\
\hline
\end{tabular}

*Gastric emptying time

History of all the patients were also assessed and it was observed that correlation between gastric emptying time and duration of the diabetes was not statically significant $(P$-value $=0.148)$.

\section{Discussion}

Results of present study which was performed on patients with diabetes and normal individuals revealed that there is statistically significant difference in gastric empting half time of these two groups. Diabetes can affect normal function of some parts of neural systems. This phenomena leads to malfunction of gastric system, consequently results in delay in gastric emptying. Our finding was in line with previous observation by Samsom et al. [15]. They reported that gastric emptying in patients with diabetes was slower than in normal volunteers. While in that study observed delay was reported in $28 \%$ of patients but in our study gastric emptying delay was reported in all of the patients. Also, in a study performed by Jones et al. on 101 patients with diabetes (79 type 1 and 22 type 2 ) to evaluate predictors of delayed gastric emptying, they reported that gastric emptying was delayed in $65 \%$ of these patients [16]. This difference may be because of correlation between gastric emptying delay and type of the diabetes which was not investigated in our study.

In diabetic patients of our study, any significant association was not found between gastric emptying and sex. Gastric emptying half time $( \pm$ SD) in diabetic men and in diabetic women was 109.87 $( \pm 28.47)$ hours and $110.78( \pm 25.08)$ hours, respectively. This finding was in contrast with results of previous studies by Samsom et al. [15] and Joens et al. [16] indicating that gastric emptying was slower in diabetic women than in diabetic men. One possible reason for this disagreement may be small number of subjects studied in our study which should not be excluded. In order to more detail evaluate of this reason another study with a larger sample is recommended.

Based on the results of laboratory findings of the patients enrolled in this study, there was no correlation between blood sugar and delayed gastric emptying, but significant correlation was observed between gastric emptying time and serum $\mathrm{HbA}_{1 \mathrm{c}}$ levels. Our finding was in a line with findings of Schvarcz et al. [17] who concluded that any changes in blood glucose may have a significant effect on gastric emptying time. This was found in both normal subjects and patients with insulin dependent diabetes mellitus. But our results was in contrast with results of the study by Reddy et al, which was performed on 250 diabetic patients [18]. Their study was a retrospective study on $\mathrm{HbA}_{1 \mathrm{c}}$ level near the performance of gastric emptying scintigraphy. As it was indicated by the authors, because of this limitation it was not possible to assess preprandial or postprandial glucose values. Therefore they recommended further studies to prospectively evaluate more factors such as postprandial glycemia, serum $\mathrm{HbA}_{1 \mathrm{c}}$ levels and duration of diabetes in order to further elucidate the effect of these variables on gastric emptying time. Our study, as such a study and beside assessment of other variables, also evaluated $\mathrm{HbA}_{1 \mathrm{c}}$ levels and duration of diabetes and resulted in observation of correlation between $\mathrm{HbA}_{1 \mathrm{c}}$ levels and gastric emptying time.

\section{Conclusion}

In patients with type 2 diabetes, delayed gastric emptying time was statistically correlated to $\mathrm{HbA}_{1 \mathrm{c}}$ level, but not to sex, age group, blood sugar concentration and duration of diabetes.

\section{References}

1. Hasler WL. Gastroparesis: symptoms, evaluation, and treatment. Gastroenterology clinics of North America 2007; 36: 619-647.

2. Annese V, Bassotti G, Caruso N et al. Gastrointestinal motor dysfunction, symptoms, and neuropathy in noninsulin-dependent (type 2) diabetes mellitus. Journal of clinical gastroenterology. 1999; 29: 171-177.

3. Horowitz M, Fraser R. Disordered gastric motor function in diabetes mellitus. Diabetologia 1994; 37: 543-551.

4. Horowitz M, Maddox AF, Wishart JM, Harding PE, Chatterton BE, Shearman DJ. Relationships between oesophageal transit and solid and liquid gastric emptying in diabetes mellitus. Eur J Nucl Med 1991; 18: 229-234.

5. Keshavarzian A, Iber FL, Vaeth J. Gastric emptying in patients with insulin-requiring diabetes mellitus. The American journal of gastroenterology. 1987; 82: 29-35.

6. Pfaffenbach B, Wegener M, Adamek RJ et al. Non-invasive $13 \mathrm{C}$ octanoic acid breath test for measuring stomach emptying of a solid test meal - correlation with scintigraphy in diabetic patients and reproducibility in healthy probands. Zeitschrift fur Gastroenterologie. 1995; 33: 141-145.

7. Jones KL, Horowitz M, Wishart MJ, Maddox AF, Harding PE, Chatterton BE. Relationships between gastric emptying, intragastric meal distribution and blood glucose concentrations in diabetes mellitus. Journal of nuclear medicine : official publication. Soc Nucl Med 1995; 36: 2220-2228.

8. Talley NJ, Vakil NB, Moayyedi P. American Gastroenterological Association Technical Review on the Evaluation of Dyspepsia. Gastroenterology. 2005; 129: 1756-1780.

9. Griffith $\mathrm{GH}$, Owen GM, Kirkman S, Shields R. Measurement of rate of gastric emptying using chromium-51. Lancet 1966; 1: 1244-1245.

10. Kong MF, Horowitz M, Jones KL, Wishart JM, Harding PE. Natural history of diabetic gastroparesis. Diabetes Care 1999; 22: 503-507.

11. Nowak TV, Johnson CP, Kalbfleisch JH et al. Highly variable gastric emptying in patients with insulin dependent diabetes mellitus. Gut 1995; 37: 23-29.

12. Soykan I, Sivri B, Sarosiek I, Kiernan B, McCallum RW. Demography, clinical characteristics, psychological and abuse profiles, treatment, and long-term follow-up of patients with gastroparesis. Digestive diseases and sciences. 1998; 43: 2398-2404.

13. Samsom $M$, Akkermans $L M$, Jebbink RJ, van Isselt $H$, vanBerge-Henegouwen GP, Smout AJ. Gastrointestinal motor mechanisms in hyperglycaemia induced delayed gastric emptying in type I diabetes mellitus. Gut 1997; 40: 641-646. 
14. Tougas $G$, Chen $Y$, Coates $G$ et al. Standardization of a simplified scintigraphic methodology for the assessment of gastric emptying in a multicenter setting. The American journal of gastroenterology. 2000; 95: 78-86.

15. Samsom M, Vermeijden JR, Smout AJ et al. Prevalence of delayed gastric emptying in diabetic patients and relationship to dyspeptic symptoms: a prospective study in unselected diabetic patients. Diabetes Care 2003; 26: 3116-3122.

16. Jones KL, Russo A, Stevens JE, Wishart JM, Berry MK, Horowitz M. Predictors of delayed gastric emptying in diabetes. Diabetes Care 2001; 24: 1264-1269.
17. Schvarcz E, Palmer M, Aman J, Horowitz M, Stridsberg M, Berne C Physiological hyperglycemia slows gastric emptying in normal subjects and patients with insulin-dependent diabetes mellitus. Gastroenterology 1997: 113: 60-66.

18. Reddy S, Ramsubeik K, Vega KJ, Federico J, Palacio C. Do HbA $\mathrm{H}_{1 \mathrm{c}}$ Levels Correlate With Delayed Gastric Emptying in Diabetic Patients? Journal of Neurogastroenterology and Motility. 2010; 16: 414-417. 